\title{
RANGE EXTENSION OF SOUTHERN CHASMOSAURINE CERATOPSIAN DINOSAURS INTO NORTHWESTERN COLORADO
}

\author{
STEVE DIEM ${ }^{*}$ AND J. DAVID ARCHIBALD \\ Department of Biology, San Diego State University, San Diego, California 92182-4614, < steve@geolabsswv.com> and \\ $<$ darchibald@ sunstroke.sdsu.edu $>$
}

\section{INTRODUCTION}

$\mathrm{T}$ HE WILLIAMS Fork Formation preserves a diverse dinosaur fauna containing at least nine saurischian and five ornithischian species. Among the dinosaur specimens recovered is a partial ceratopsian skull (SDMNH 43470) referable to the ceratopsid subfamily Chasmosaurinae (Diem, 1999). Chasmosaurines, or long-frilled ceratopsians, existed throughout western North America during the Campanian and Maastrichtian (Judithian, Edmontonian, and Lancian). Recent discoveries have renewed debate over the phylogenetic relationships and biogeographic history among the chasmosaurines (Forster et al., 1993; Lehman, 1996; Holmes et al., 2001).

There are some latitudinal differences in occurrences of taxa. Northern chasmosaurines include Anchiceratops ornatus (Brown, 1914), Chasmosaurus belli (Lambe, 1902), C. irvinensis (Holmes et al., 2001), and C. russelli (Sternberg, 1940) from the upper Campanian Dinosaur Park Formation of Alberta, Canada (Dodson and Currie, 1990; Godfrey and Holmes, 1995; Holmes et al., 2001; Ryan and Russell, 2001). A. ornatus has also been reported from the upper Campanian to Maastrichtian Horseshoe Canyon Formation of Alberta, Canada (Eberth, 1997), as has Arrhinoceratops brachyops (Parks, 1925; Dodson and Currie, 1990). The common late Maastrichtian species Triceratops horridus (Marsh, 1889) ranges from Colorado in the south to Alberta and Saskatchewan in the north, while the less common Torosaurus latus (Marsh, 1891) has a slightly smaller, but similar range (Dodson and Currie, 1990), both occurring in the Lance and Hell Creek Formations or their equivalents. In the southern area, another Maastrichtian species of Torosaurus (Marsh, 1891), T. utahensis (Gilmore, 1946) from the North Horn Formation of Utah, Kirtland Shale in northwestern New Mexico, and the Javelina Formation of southwestern Texas, is sometimes recognized (Lehman, 1996). Some authors treat Torosaurus utahensis as a synonym of T. latus (Dodson and Currie, 1990). If this synonymy is correct, T. latus maintained a geographic range from Saskatchewan, Canada, in the north to Texas and New Mexico in the south (Dodson and Currie, 1990). There is also a southern species of Chasmosaurus (Lambe, 1902), C. mariscalensis (Lehman, 1989), recognized from the Campanian Aguja Formation of Texas (Lehman, 1989), and the unnamed "El Picacho ceratopsian" from the Maastrichtian El Picacho Formation of Texas (Lehman, 1996). The monospecific Pentaceratops (Osborn, 1923), from the upper Campanian to lower Maastrichtian Fruitland Formation and Kirtland Shale (Lehman, 1993) of New Mexico, is the only chasmosaurine genus that has to date been restricted to the southwest.

The specimen recovered from the Williams Fork Formation of northwestern Colorado is of interest because it appears to be most closely related if not conspecific with one of the more southern chasmosaurines (Lehman, 1993), either Chasmosaurus mariscalensis or Pentaceratops sternbergi (Osborn, 1923). The specimen * Present address: 29756 Mammoth Lane, Canyon Country, California
91387. is noteworthy because it expands the geographic distribution of southern chasmosaurines into northwestern Colorado.

Institutional abbreviations.-AMNH, American Museum of Natural History; MNA, Museum of Northern Arizona; NMC, Canadian Museum of Nature; PMU, Paleontological Institute of Uppsala University; SDNHM, San Diego Natural History Museum; TMP, Royal Tyrrell Museum of Palaeontology; SDSU, San Diego State University; UKVP, University of Kansas Museum of Vertebrate Paleontology; UNM, University of New Mexico.

\section{PALEOGEOGRAPHY, STRATIGRAPHY, AND BIOSTRATIGRAPHY}

During Late Cretaceous time, the western shoreline of the Western Interior Sea migrated back and forth across the interior of North America as the sea level rose and fell. As the shoreline migrated eastward across Colorado during middle Campanian time, the littoral Castlegate Sandstone was deposited (Noll, 1988; Lillegraven and Ostresh, 1990). A minor westerly migration of the shoreline resulted in the marine Buck Tongue of the Mancos Shale (Noll, 1988). As the shoreline returned to its easterly migration, thinly bedded marine siltstones, mudstones, and very fine sandstones of the Mancos Shale were overlain by the littoral Sego Sandstone (Lawton, 1986). The overlying Iles Formation preserves deposits of swamp, lacustrine, and fluvial distributary channel environments (Kitely, 1983), with the uppermost unit being the shallow marine Trout Creek Sandstone (Dyni, 1968; Cullins, 1971). Fluvial sediments of the Williams Fork Formation were deposited on top of the Trout Creek Sandstone in coastal plain environments along the western edge of the Western Interior Sea (Lawton, 1983, 1986; Zeiler, 1987; Noll, 1988).

Deposition of the Williams Fork Formation ceased during the penultimate transgressive episode of the Western Interior Sea (Noll, 1988). Conformably overlain by the Lewis Shale in the type locality (Hancock, 1925), the Williams Fork Formation is unconformably overlain by the Wasatch Formation (Archibald, 1987; Noll, 1988), south of Rangley.

The relative age of the Williams Fork Formation is well constrained based on ammonite zonation (Fig. 1). The ammonites Baculites perplexus (Cobban, 1962) and B. scotti (Cobban, 1958) have been found in the upper part of the Mancos Shale (Newman, 1987). In the overlying Iles Formation, the marine shale below the Trout Creek Sandstone member contains the ammonite Exiteloceras jenneyi (Whitfield, 1877). In addition, a number of ammonites have been recovered from within the Williams Fork Formation. Didymoceras cheyennense (Meek and Hayden, 1856) has been found in the lower part of the Williams Fork Formation and Baculites reesidei (Elias, 1933) has been recovered from the marine shale below the Twenty-Mile Sandstone Member (Newman, 1987). Pollen from the upper Williams Fork Formation was reported by Cullins (1971) and interpreted as similar to pollen found in the Fox Hills Sandstone and basal part of the Lance Formation, Wyoming (Gill and Cobban, 1966).

The Williams Fork Formation represents a period spanning seven ammonite zones from the Didymoceras cheyennense to the Baculites baculus (Meek and Hayden, 1861) Zone (Newman, 1987). Based on the timescale of Obradovich and Cobban (1975), 


\section{Rio Blanco County}

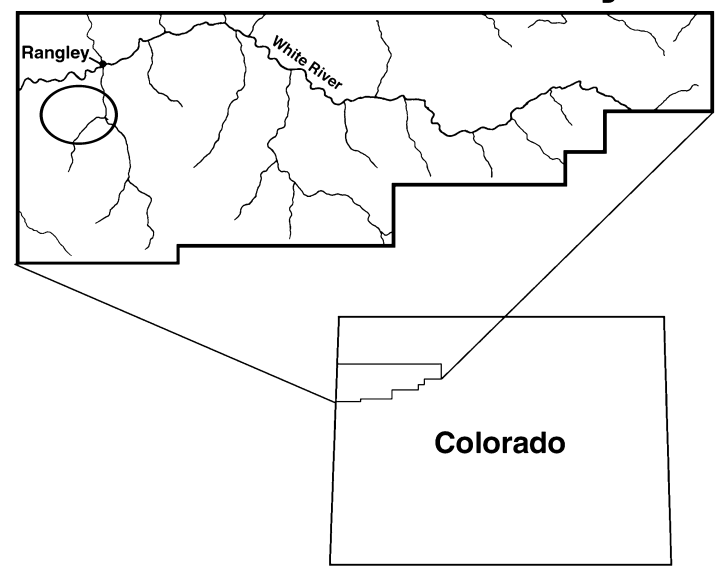

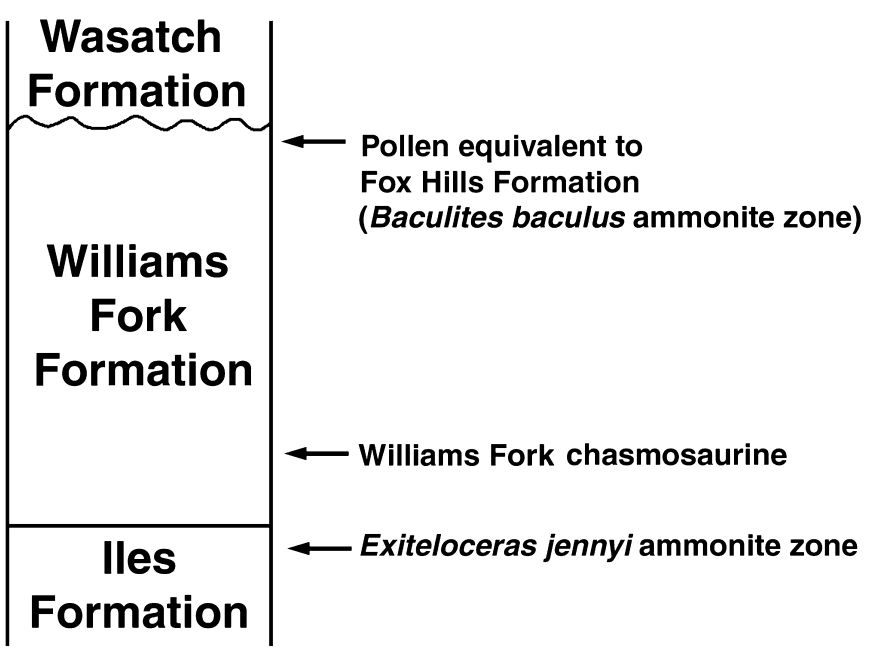

FIGURE 1-The Williams Fork chasmosaur was recovered (within ellipse) south of Rangley, Rio Blanco County, northwestern Colorado. The stratigraphic column indicates the approximate location of the Williams Fork chasmosaur and the location of ammonites and pollen used to determine the age of the Williams Fork fauna.

these seven ammonite zones represent approximately three million years, correlative with the late Campanian to early Maastrichtian (Harland et al., 1990). Lillegraven and Ostresh (1990) correlated these seven ammonite zones to the "Edmontonian" North American Land Mammal "Age” (NALMA).

\section{SYSTEMATIC PALEONTOLOGY \\ Order ORNITHISCHIA Seeley, 1888 \\ Family CERATOPSIDAE Marsh, 1888 \\ Subfamily CHASMOSAURINAE Lambe, 1915 \\ Genus and species INDETERMINATE}

Description.-SDNHM 43470, a partial skull, consists of the predentary and elements from the right side of the skull, including: maxillary fragment (containing 17 teeth), jugal, quadratojugal, inferior parts of the braincase, nearly complete right squamosal, median and lateral fragments of the parietal, pterygoid, quadrate, and parts of the right dentary. Figure 2 is a reconstruction of the skull and lower jaw in a right lateral view. Based on this reconstruction, the maximum length from the posterior edge of the posteriormost epoccipital to the anterior tip of the predentary measured about $1,300 \mathrm{~mm}$.

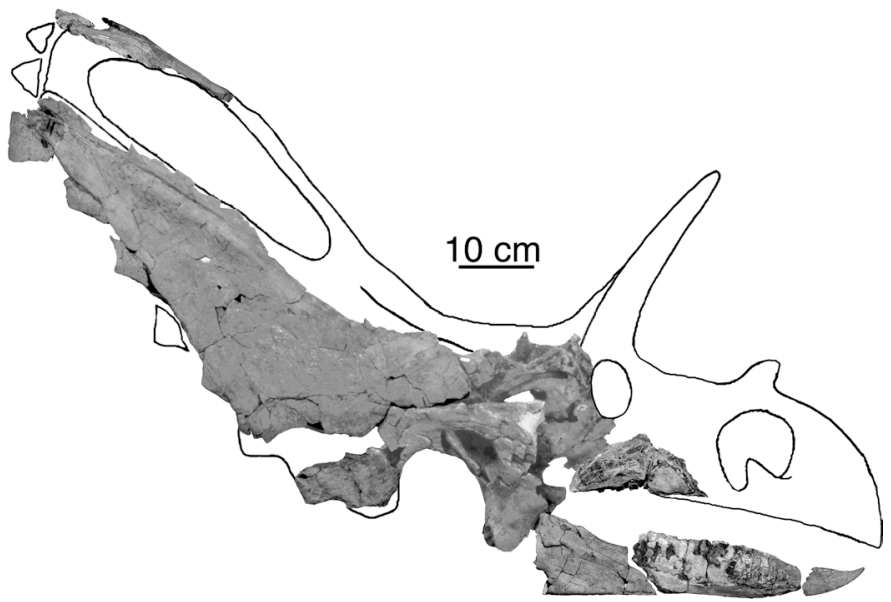

FIGURE 2-Right lateral view of elements recovered of the Williams Fork chasmosaur, SDNHM 43470, superimposed on a generalized chasmosaurine skull.

Maxilla and Dentition: The right maxilla fragment represents a section posterior to the ascending ramus. Posteriorly, the preserved portion meets the pterygoid via the intervening palatine (Fig. 3). On the lateral surface, a ridge extends from the preserved posterior limit of the maxilla to its preserved anterior limit. There are 17 teeth preserved in the maxillary fragment, in variable degrees of eruption. The teeth are similar to those of other ceratopsians.

Quadrate: A nearly complete right quadrate is preserved with only the posteriormost portions missing or obscured by other cranial elements (Figs. 3, 4). The preserved length is approximately $205 \mathrm{~mm}$, while the greatest preserved width is $125 \mathrm{~mm}$ across the pterygoid wing. Laterally, the quadrate articulates with the quadratojugal for more than two-thirds of its length (Fig. 3). At the distal end, this contact has been separated $5 \mathrm{~mm}$ by postmortem distortion. Medially, the quadrate articulates with the pterygoid via a strongly developed but thin pterygoid flange. It is approximately $2 \mathrm{~mm}$ thick along the preserved medial edge. The portion of the pterygoid that would normally contact the pterygoid flange of the quadrate is broken, revealing the smooth underlying surface of the quadrate (Fig. 4). The condyle measures $78 \mathrm{~mm}$ mediolaterally and $22 \mathrm{~mm}$ anteroposteriorly. The distal surface of the condyle has a very rough texture. Proximal to the condyle, the quadrate is constricted to $52 \mathrm{~mm}$ mediolaterally, with a smooth texture on the lateral surface.

Jugal: Posterior and ventral portions of the right jugal are preserved, connecting to the quadratojugal medially and to the squamosal posteriorly, dorsal to the lateral temporal fenestra. These bones were found in articulation or nearly so. Although the edge is broken, the jugal and squamosal likely did not contact below the lateral temporal fenestra; the edges of the jugal and squamosal are approximately 1-2 $\mathrm{mm}$ thick and are separated by $75 \mathrm{~mm}$. Distally, the jugal broadens laterally forming the lateral half of the contact with the epijugal (not preserved). Along its anterior border the jugal possesses a notch approximately $20 \mathrm{~mm}$ high and $25 \mathrm{~mm}$ deep (identified as jugal notch on Fig. 3). The bone texture around this notch is striated and funnels toward the notch. On the inferior border of the notch is a small dorsally directed process measuring $4 \mathrm{~mm}$ wide at its base and $5 \mathrm{~mm}$ high. Because of the thinning of the bone around the notch and the distinctly striated surface, this feature appears to be a true osteological structure rather than a preservational artifact. It, however, may be the result 


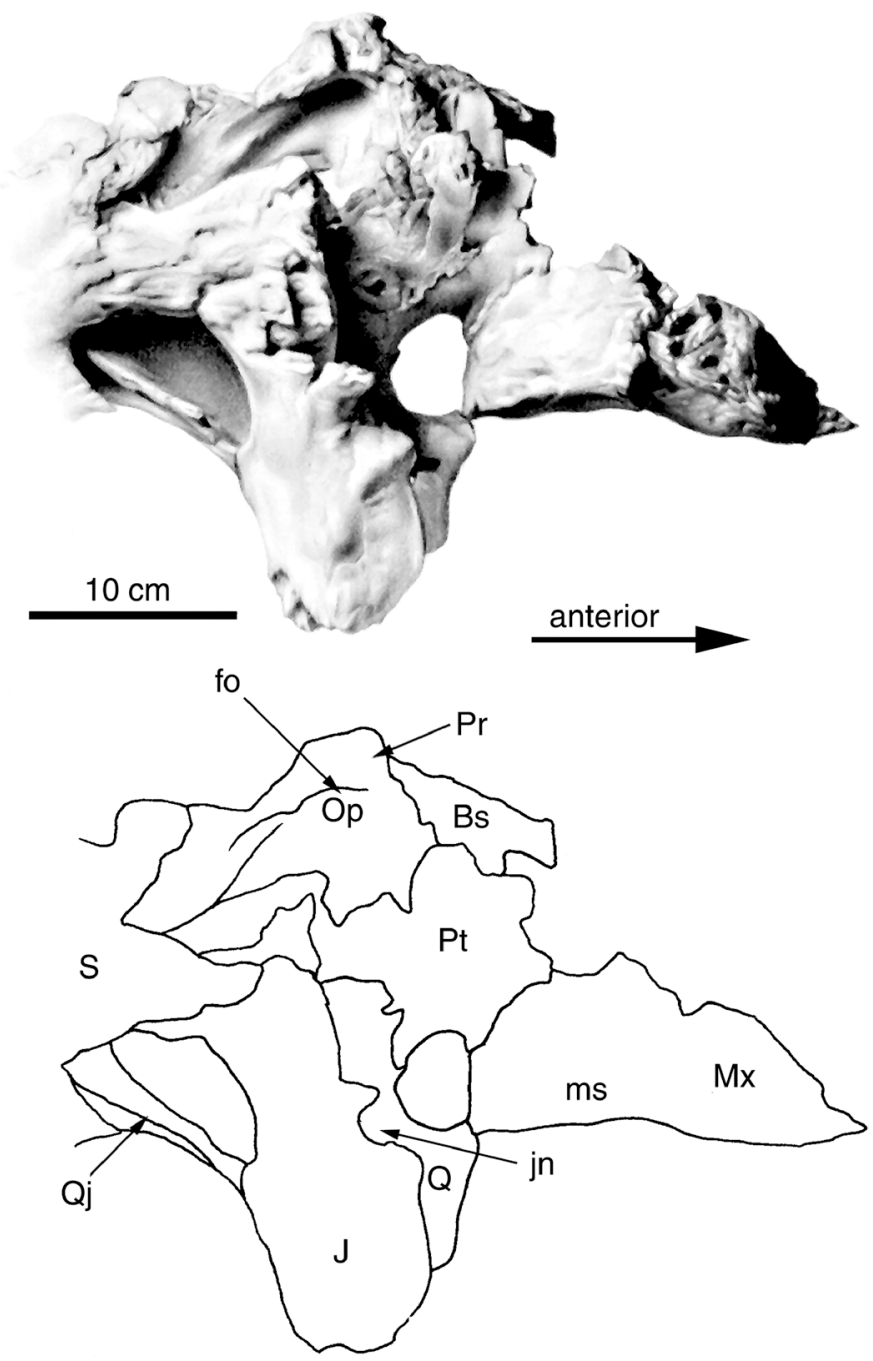

FIGURE 3-Williams Fork chasmosaur, SDNHM 43470, right cranial fragment, lateral view. Abbreviations: Bs, basisphenoid; fo, foramen ovalis; J, jugal; jn, jugal notch; ms, maxillary shelf; Mx, maxilla; Op, opisthotic; Pr, prootic; Pt, pterygoid; Q, quadrate; Qj, quadratojugal; S, squamosal.

of some premortem pathology, and additional specimens are necessary before one can state with confidence that this feature is the result of taxonomic variation.

Quadratojugal: The right quadratojugal is preserved in articulation with the jugal laterally and quadrate medially (Fig. 4). It forms the ventral border of the lateral temporal fenestra, although postmortem distortion has rotated its caudal end dorsally. Rostrally the quadratojugal broadens to form a triangular block between the quadrate and jugal. This block appears to form the medial half of the contact for the epijugal, which is not preserved.

FIGURE 4-Williams Fork chasmosaur, SDNHM 43470, right cranial fragment, posterior view. Occipital condyle is in normal anatomical position with lateral elements (e.g., distal end of quadrate) showing some displacement medially. Abbreviations: Bs, basisphenoid; bt, basioccipital tuber; Eo, exoccipital; J, jugal; oc, occipital condyle; pp, paroccipital process; Pt, pterygoid; Q, quadrate; Qj, quadratojugal; S, squamosal.

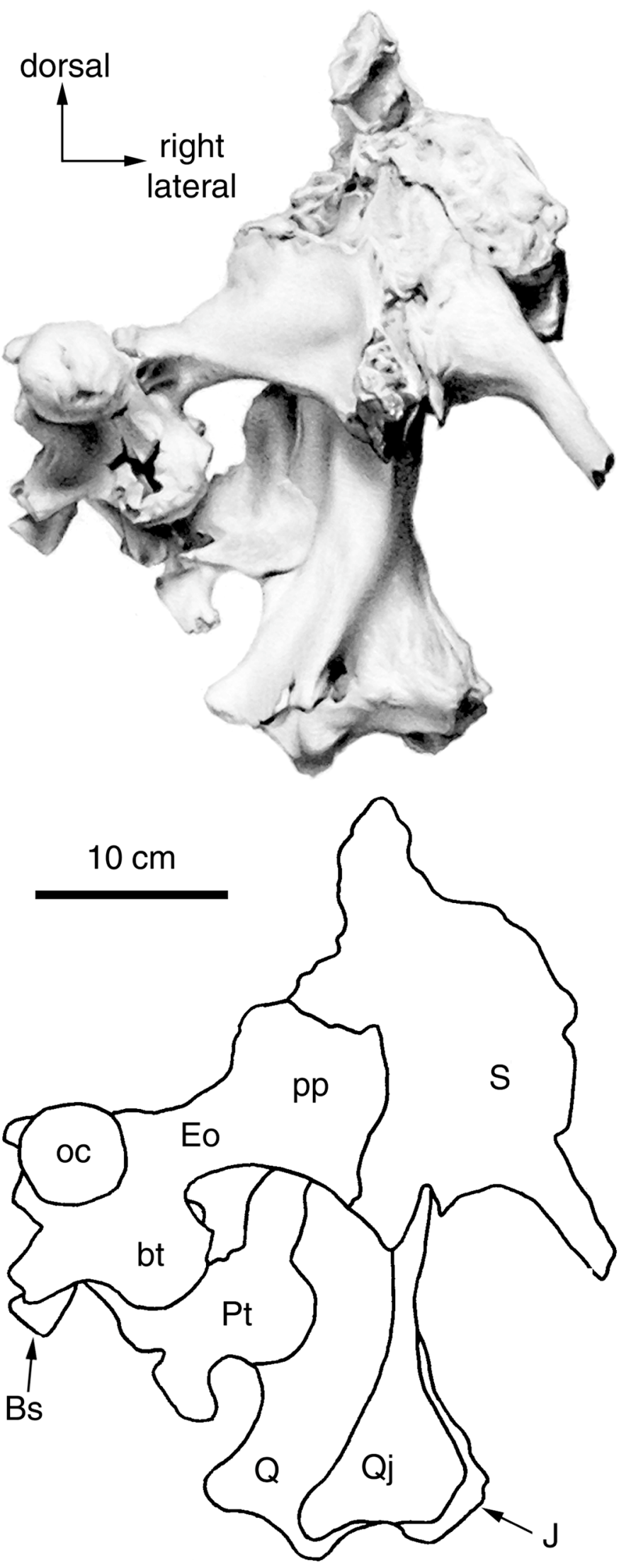




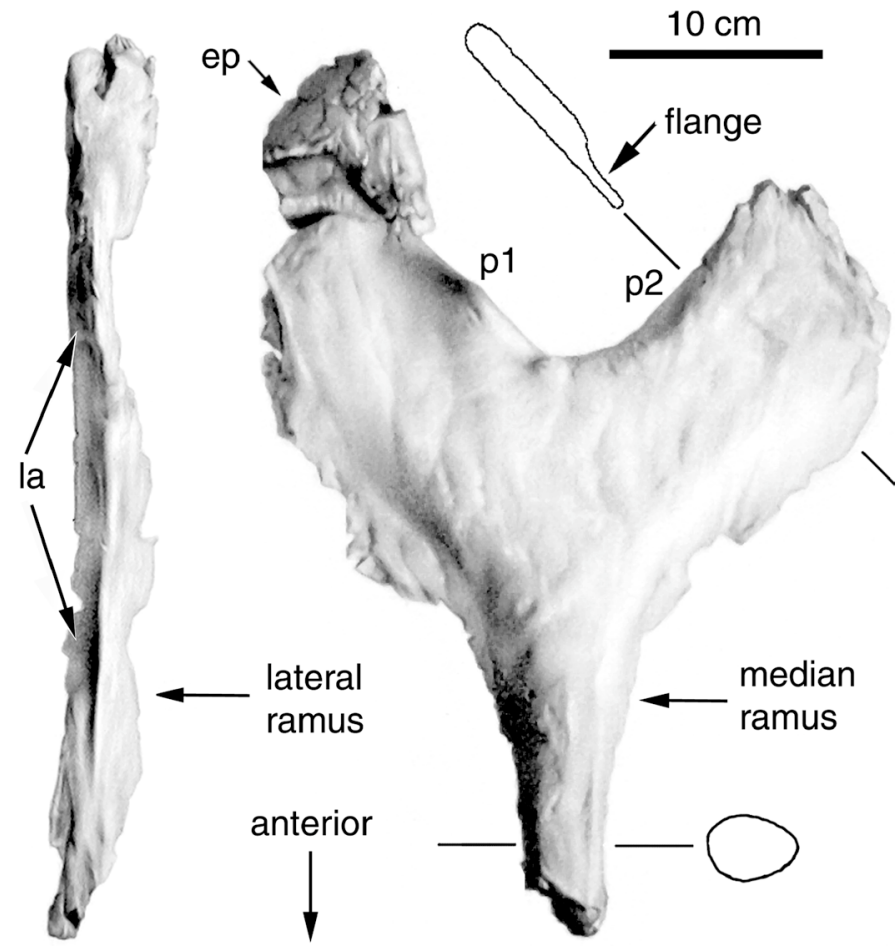

FIGURE 5-Williams Fork chasmosaur, SDNHM 43470, right lateral parietal fragment and part of median ramus. Abbreviations: ep, epoccipital; la, lateral articulating surface for squamosal; $\mathrm{p} 1, \mathrm{p} 2$, processes discussed in text.

A thin $(<1 \mathrm{~mm}$ thick) portion of the quadratojugal extends dorsally to underlie the jugal for $48 \mathrm{~mm}$ across most of the width of the jugal.

Parietal: The parietal is represented by two fragments, a Yshaped median segment and a slender lateral ramus that runs along the medial edge of the squamosal (Fig. 5). These fragments demonstrate similarities with chasmosaurines such as Pentaceratops sternbergi (Lull, 1933; Rowe et al., 1981; Lehman, 1993).

The Y-shaped segment consists of the posterior end of the median ramus, medial ends of both transverse rami, and a single preserved epoccipital (Fig. 5). The anterior end of the preserved portion of the median ramus is oval in cross section, similar to that found in species of Chasmosaurus (Lehman, 1990) and Pentaceratops sternbergi (Lehman, 1993). Posteriorly, the median ramus flattens and bifurcates into transverse rami. The lateral margins of the transverse rami flatten further into flanges surrounding the parietal fenestra.

The posterior border of the parietal is strongly indented along the midline, similar to that in the Pentaceratops sternbergi specimens AMNH 1625 and MNA P1.1747. The surface texture of the median segment of the parietal ranges from smooth to striated (Sampson et al., 1997) with the ventral surface typically containing long-grained texture. The dorsal surface has relatively more abundant but shorter channels. These textures suggest that this individual's death occurred at a time of continuing bone growth. This type of bone texture is indicative of an immature individual (Sampson et al., 1997).

There is a partial epoccipital on the posterior margin of the right transverse ramus. Enough is preserved to indicate how the epoccipital was attached to the parietal. It shows the epoccipital resting on a process extending from the parietal into the epoccipital for approximately half its preserved height. A corresponding process is present on the left transverse ramus, but an associated epoccipital was not recovered. The triangular epoccipital is slightly greater in basal length than in height and contains abundant deep groves, possibly for vascularization. It lies in the same plane as the parietal and is directed posterodorsally (Fig. 5).

Two additional, albeit smaller, processes are present along the posterior emargination of the parietal. One is approximately midway between the midline of the parietal and the preserved epoccipital. The other occupies a similar position on the left side, though the latter process is somewhat smaller. The area around these processes is striated. It is likely that upturned epoccipitals rested on these processes. It can be inferred that because of the putatively immature nature of the specimen, the upturned epoccipitals were either present but not fused to the processes and were subsequently lost, or they had not yet formed. The absence of the upturned epoccipitals from SDNHM 43470 does not preclude the specimen from referral to Pentaceratops. The preserved posterior portion of the frill in specimens PMU.R200 and UKVP 16100, referred to $P$. sternbergi, also do not have the upturned epoccipitals. Lehman (1993) indicated that their presence on Pentaceratops sternbergi may be variable. In support of the variable presence of accessory cranial elements in other chasmosaurines, Lehman (1993, p. 284-285) points out "an undescribed specimen (TMP P83.1.1), which is otherwise identical to Anchiceratops but apparently lacks the hook-like processes, may still be referable to Anchiceratops." Godfrey and Holmes (1995) discussed variation of the epoccipitals in Chasmosaurus. The parietal epoccipitals almost always numbered three on each side, but one specimen had four on both sides. There was no indication that any of the epocciptals was hook-like.

The right lateral ramus is long and slender with a flat, triangular cross section along the anterior two-thirds of its preserved length (Fig. 5). Posteriorly, the edges gradually become rounded while the cross section grades into a flattened oval before tapering, a morphology indicating that the terminus was just beyond the broken edge. Therefore, the parietal did not extend past the distal end of the squamosal more than $20-30 \mathrm{~mm}$. The lateral articulating surface that fits into the parietal recess of the squamosal is preserved over the entire length of the fragment (Fig. 2).

Squamosal: A nearly complete right squamosal (total length, $765 \mathrm{~mm}$ ) is preserved, with six attached epoccipitals and contact surfaces for three more (Fig. 6). As with most other chasmosaurines, the squamosal is triangular in lateral view. The thickened medial and lateral borders thin toward the interior of the bone, creating a concave dorsolateral surface. The medial edge ranges from a minimum thickness of $14 \mathrm{~mm}$, near midlength, to $28 \mathrm{~mm}$ along the parietal recess at its posterior end. The deep parietal recess is well defined from the posteriormost end of the squamosal to the position of epoccipital 8, where it grades into a flat surface that rotates from the posterior edge of the squamosal to its medial surface.

Based on the size and positions of the six epoccipitals preserved, the Williams Fork specimen had nine epoccipitals on the squamosal. The morphology and number of epoccipitals on the squamosal agree with descriptions of $P$. sternbergi (eight to 12 epoccipitals; Lehman, 1993). Of the six preserved, epoccipitals 2, 4 , and 5 are co-ossified with the lateral margin. The suture between each epoccipital and the lateral edge of the squamosal is clearly visible. Epoccipitals 7-9 are not sutured to the squamosal, but were preserved in situ. Epoccipitals 7 and 8 are considerably longer than 2, 4, and 5, but only slightly taller. Epoccipitals 7 and 8 are shorter and broader than the terminal epoccipital, which is only slightly taller than it is wide.

The lateral edge of the squamosal, from epoccipital $1-7$, is markedly thickened near the points of epoccipital attachment and is constricted between the attachments. This variation in thickness diminishes near the midline of epoccipital 8 , giving way to a 


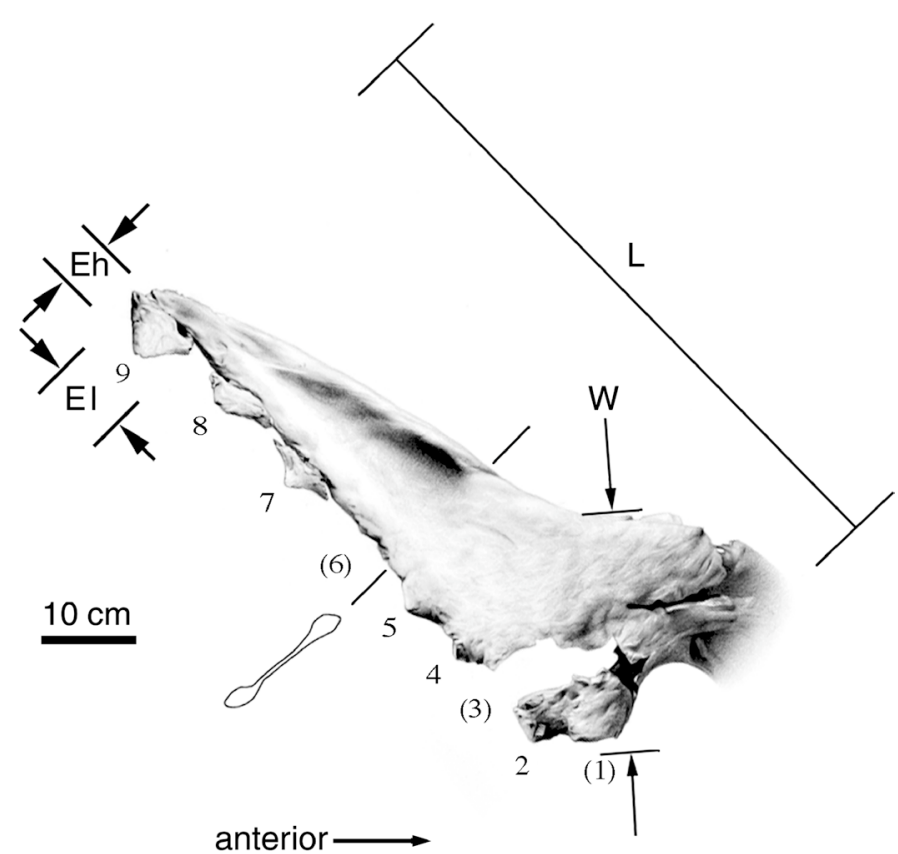

FIGURE 6-Williams Fork chasmosaur, SDNHM 43470, right squamosal, SDNHM 43470, lateral view. Numbers indicate the relative position of each epoccipital, parentheses indicate presumed epoccipital location. Abbreviations: Eh, epoccipital height; El, epoccipital length; L, length; W, width.

solid, uniformly thick lateral margin. The attachment surfaces for the squamosal epoccipitals are concave, while they are convex for the parietal epoccipitals.

The thickness of the lateral edge of the squamosal varies along its length. At the attachment sites for epoccipital 1 and 2 the lateral border is $25 \mathrm{~mm}$ and $20 \mathrm{~mm}$, respectively. Epoccipital 3 as well as the lateral border of the squamosal at that location are not preserved. The lateral edge of the squamosal is $30 \mathrm{~mm}, 27$ $\mathrm{mm}, 25 \mathrm{~mm}, 21 \mathrm{~mm}, 16 \mathrm{~mm}$, and $17 \mathrm{~mm}$ in thickness, at epoccipitals 4-9, respectively. Epoccipital 9 extends approximately 15 $\mathrm{mm}$ past the distal end of the squamosal.

The terminal epoccipital (the one at or near the caudal end of the squamosal and considerably taller than the adjacent squamosal epoccipital) on the right squamosal of SDNHM 43470 (epoccipital 9) appears to have overlapped the squamosal-parietal contact. This condition is similar to that of AMNH 1625 referred to Pentaceratops sternbergi where epoccipitals overlap the contact on both the right and left corners of the frill.

Lehman (1996, p. 499), in describing the third epoccipital from the anterior end of the right squamosal preserved on the "El Picacho ceratopsian" from west Texas (TMM 42304-1), states "this epoccipital is low and elongate, similar to those found in Torosaurus (e.g., Gilmore, 1946), and unlike the peaked triangular forms typical in some specimens of Pentaceratops and Chasmosaurus." Epoccipitals preserved on the lateral border of the squamosal of the Williams Fork chasmosaurine maintain the triangular morphology consistent with Pentaceratops and Chasmosaurus.

It is apparent that epoccipitals 2, 3, and 5 fused to the margin before epoccipitals 7-9. This relative order of fusion agrees with other chasmosaurines where the epoccipitals suture to the squamosal beginning at the anterior end and progressing posteriorly (Lehman, 1989). This appears to be opposite to the condition seen in centrosaurines where the epoccipitals fuse to the squamosal beginning posteriorly (Sampson et al., 1997).

Braincase: The preserved ventral portion of the braincase is comprised of parts of the basioccipital, basisphenoid, exoccipitals, right opisthotic, and prootic. Laterally, the braincase articulates with the squamosal via the paroccipital processes of the exoccipital (Fig. 4). The occipital condyle ( $53 \mathrm{~mm}$ wide) is elliptical, compressed dorsoventrally, with its neck slightly constricted. Only the posteroventral portions of the elements that form the foramen magnum are preserved, suggesting a transverse width of approximately $30 \mathrm{~mm}$. Posterior to the right paroccipital process, the foramina that carried cranial nerves IX-XI are present (Lehman, 1993), while poor preservation has distorted the foramen for cranial nerve XII (Lehman, 1993). Anterior to the paroccipital process are two foramina. The most posterior of these is the fenestra ovalis, while the anterior is the passage for cranial nerve VII (Lehman, 1993). Unlike most of the other cranial bones, the elements in and around the braincase are completely fused, showing no signs of postmortem separation.

Pterygoid: The right pterygoid is preserved in articulation with the pterygoid wing of the quadrate laterally and the basisphenoid medially (Fig. 4). Anteriorly, the pterygoid is fused to the maxilla. Posteriorly, the pterygoid thins to less than $1 \mathrm{~mm}$ in thickness.

Dentary: Two fragments of the right dentary are preserved (Fig. 2 ). The right anterior dentary fragment is $230 \mathrm{~mm}$ long and 80 $\mathrm{mm}$ tall. Several of the alveoli are discernible, but no teeth are preserved. The ventral surface is rounded and smooth.

The second dentary fragment is the posteriormost section that includes the base of the coronoid process and the contacts for the angular and surangular. The medial surface preserves the posterior limit of the Meckelian canal. The ventral surface of the fragment is flat over the preserved length of $143 \mathrm{~mm}$. On the lateral surface there is a separate ossification directed ventrally, possibly a fragment of the surangular fused to the base of the coronoid process. Several foramina are present along the lateral surface, anterior to the base of the coronoid process. This dentary fragment is similar to the dentary found in association with a skull referable to Pentaceratops sternbergi, MNA P1. 1747.

Predentary: A nearly complete, undistorted predentary is preserved, lacking only the posterior processes. The ventral surface is highly vascularized with the foramina concentrated at the distal end (Fig. 7). The cutting surfaces of the predentary are concave in lateral view. The inclination grades from approximately zero at the distal end to approximately 15 degrees at the proximal end.

There are several differences between the predentary from the Williams Fork chasmosaurine and those of Pentaceratops sternbergi described by Lehman (1993). First, dimensions of the two predentaries assigned to $P$. sternbergi (UNM FKK-081, length $=$ $230 \mathrm{~mm}$, width $=167 \mathrm{~mm}$; UNM B-810a, length $=209 \mathrm{~mm}$, width $=129 \mathrm{~mm}$ ), are significantly larger than the predentary of the Williams Fork specimen (length $=150 \mathrm{~mm}$, width $=115$ $\mathrm{mm}$; these measurements are approximations because of the incompleteness of the specimen). In addition, the Williams Fork specimen does not show the pronounced medial groove on its ventral surface as seen on specimens referred to Pentaceratops sternbergi (Lehman, 1993). There is, however, a shallow medial groove on the posterior half of the predentary (Fig. 7). The lack of a pronounced medial groove, as well as the smaller dimensions, are likely the result of the immature nature of the individual.

Ontogenetic age determination: In determining the ontogenetic age of the Williams Fork specimen, several factors may be evaluated, including periosteal aging, fusion of cranial elements, fusion of accessory dermal ossifications, and size and proportions of cranial elements. Sampson et al. (1997) described a method for estimating the relative age of ceratopsian individuals based on bone texture. The Williams Fork specimen has a range of surface textures including mottled, smooth, and striated (Sampson, personal commun.). This combination of features is characteristic of a subadult individual (Sampson et al., 1997). 

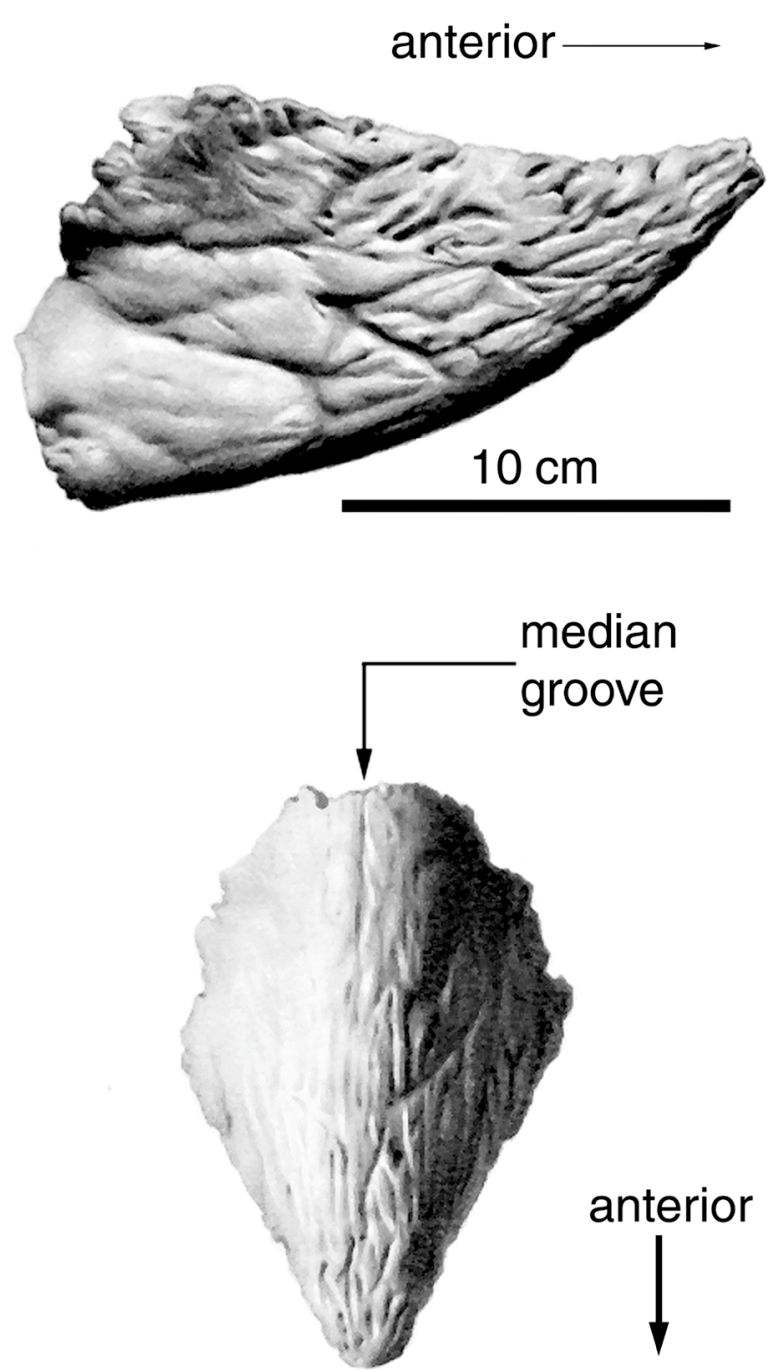

FIGURE 7-Williams Fork chasmosaur, SDNHM 43470, predentary, SDNHM 43470, right lateral view (above), ventral view (below).

Many of the cranial sutures are still visible or have been opened by postmortem distortion. The lack of fusion between cranial bones of the Williams Fork specimen indicates that this animal was not fully mature at the time of death. The only sutures that cannot confidently be identified are those between the parietals and around the braincase, which include those sutures between the paroccipital process, opisthotic, prootic, and basisphenoid.

In some hadrosaurs, closure of the interparietal suture does not help in differentiating juvenile and subadult individuals, because they often close early in embryonic development (Horner and Currie, 1994). Similarly, Dodson and Currie (1988) reported no indication of a suture between the parietals of a juvenile ceratopsian from the Dinosaur Park Formation. Thus, lack of sutures between parietals in the Williams Fork specimen is not indicative of adult status.

Lehman (1989, p. 146) suggested that "the stage at which epoccipitals begin to fuse to the margins of the squamosal ... may serve as an arbitrary indication of adulthood." The anterior epoccipitals on the Williams Fork specimen have fused to the edge of the squamosal. Following Lehman (1989), the fusion of the anterior epoccipitals to the margin of the squamosal would indicate that the Williams Fork specimen is an adult. The sutures between these anterior epoccipitals and the squamosal, however, are clearly visible. In presumably older specimens (e.g., Pentaceratops AMNH 1625, MNA P1. 1747), the sutures between the anterior epoccipitals and the squamosal are completely obliterated (Lehman, 1989).

Many chasmosaurines possess shorter and broader squamosals as juveniles (Lehman, 1989). The length of the right squamosal of the Williams Fork specimen is approximately $765 \mathrm{~mm}$, significantly shorter than other specimens of Pentaceratops sternbergi (MNA P1.1747 $=1,150 \mathrm{~mm}$ for the right squamosal and 1,130 $\mathrm{mm}$ for the left; the left squamosal of AMNH 6325 is approximately $1,350 \mathrm{~mm}$ ). The squamosal of the Williams Fork specimen has a length to width ratio of 2.6, while it is 3.35 for MNA P1.1747 (average ratio for the right and left squamosals), and approximately 3.0 for AMNH 6325 (measurements taken from Lull, 1933, Plate V). Thus, it is posited here that the Williams Fork specimen is a subadult individual and that the differences between the Williams Fork specimen and other chasmosaurines such as Pentaceratops sternbergi are the product of ontogenetic variation.

Material examined.-SDNHM 43470, a partial skull. The specimen was discovered in 1985 by Dawn Hammond, a member of the SDSU field crews in Rio Blanco County, northwestern Colorado (Fig. 1). Locality data are available from the San Diego Natural History Museum for qualified persons.

Occurrence.- Late Cretaceous of northwestern Colorado. The specimen was found near the top of a low cliff face about $1.5 \mathrm{~m}$ high. It was in a light gray, fine grain sandstone and siltstone lacking any apparent primary structures. The specimen consisted of only cranial and lower jaws elements that appeared to either be in contact or only slightly separated from one another. The bones were found as an isolated specimen, although bone fragments of dinosaurs, turtles, and crocodilians occur infrequently along the same exposure for several kilometers.

Discussion.-In their systematic analysis of Chasmosaurinae, Holmes et al. (2001) found that Chasmosaurus belli, C. irvinensis, and $C$. russelli form a clade united by four apomorphies. In turn, these three species, C. mariscalensis, and Pentaceratops form a tritomy united by eight apomorphies. Where possible, we examined these characters in the Williams Fork specimen. The following comparisons use the analysis of Holmes et al. (2001).

Of the four derived characters uniting Chasmosaurus belli, $C$. irvinensis, and $C$. russelli, the Williams Fork specimen can be examined for only two. According to Holmes et al. (2001), in the derived condition, the jugal intratemporal flange is present, contacting the jugal process of the squamosal to form the ventral margin of the lower temporal fenestra (their character 13). Although not complete in the Williams Fork specimen, this area is well enough preserved to indicate there was no contact of the squamosal and jugal below the lower temporal fenestra. This is the ancestral condition also retained by $C$. mariscalensis and Pentaceratops. Holmes et al. (2001) indicate (in their character 24) that in the ancestral condition the median bar of the parietal is dorsoventrally compressed, thin and straplike, and in the derived condition it is dorsoventrally deep, rectangular, square, or subcircular in cross section. This last description seems to describe the condition in the Williams Fork specimen (Fig. 5). Later in the description of this character, however, they indicate that in taxa with the ancestral condition such as $C$. mariscalensis and Pentaceratops that "the midline bar is dorsoventrally compressed and tapered laterally." This also seems to describe the Williams Fork specimen, although the thin lateral margins of the median parietal bar in this specimen are mostly broken. Accordingly, we also consider the Williams Fork specimen to be ancestral for this trait. Retention of the ancestral condition for the two characters preserved in the Williams Fork specimen seem to preclude it from 


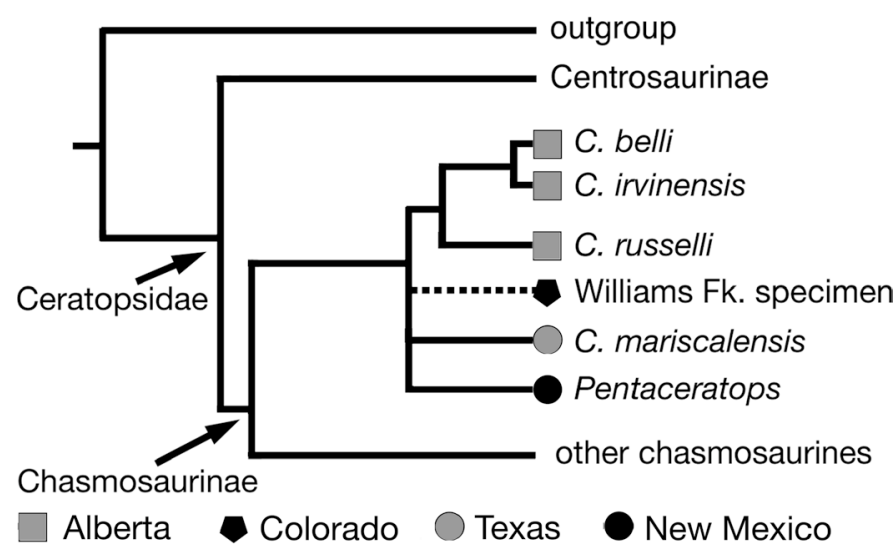

FIGURE 8-Phylogenetic anaylsis of the Chasmosaurus/Pentaceratops clade of chasmosaurines by Holmes et al. (2001) with the Williams Fork Formation hung on the tree based upon characters discussed in the text. Also shown is the northern clade from Alberta as well as the more southern taxa, including the Williams Fork specimen.

the clade composed of Chasmosaurus belli, $C$. irvinensis, and $C$. russelli.

Of the eight apomorphies that Holmes et al. (2001) found that unite all species of Chasmosaurus and Pentaceratops, three can be examined in the Williams Fork specimen. The ancestral state for character 21 of Holmes et al. (2001) is for the posterior bar of the parietal behind the parietal fenestra to be relatively wide, 0.2 or more of the total parietal length. The derived condition is for this bar to be narrow and straplike with anteroposterior width of 0.1 or less of the total parietal length. Although the parietal is not complete in the Williams Fork specimen, the preserved portion of the squamosal that bordered the parietal shows that the above ratio was no more than 0.18 and possibly as little as 0.15 . This range falls between the values of Holmes et al. (2001), but given that it is less than the ancestral value, it could be used to link the Williams Fork specimen with the Chasmosaurus/Pentaceratops clade.

The next character of Holmes et al. (2001) that can be discerned in the Williams Fork speciemen is their character 23, in which the ancestral condition is for the mediolateral width of the median bar of the parietal to be relatively wide, 0.15 or more of the total parietal length. In the derived condition it is narrow and straplike with a width less than 0.10 of total parietal length. As for the preceding character, the squamosal can be used to gauge the parietal length. For the Williams Fork specimen, the ratio appears to be less than 0.10 , which is derived. This would group the Williams Fork specimen with the Chasmosaurus/Pentaceratops clade.

Finally, the condition in the Williams Fork specimen for character 25 of Holmes et al. (2001) can be estimated. The ancestral condition, which the Williams Fork specimen appears to possess, is for the parietal to form the entire lateral margin of the parietal fenestra. In the derived condition, the parietal is discontinuous around the lateral margin of the parietal fenestra with the squamosal forming part of this margin. Holmes et al. (2001) go on to note that in all of species of Chasmosaurus (unknown in C. mariscalensis) and Pentaceratops this character is polymorphic. Thus, the presence of the ancestral condition in the Williams Fork specimen does not provide much phylogenetic information.

In combination, the characters from Holmes et al. (2001) discussed above argue that the Williams Fork specimen is most likely a member of the Chasmosaurus/Pentaceratops clade (Fig. 8). Further, where known, it lacks the apomorphies found in the clade composed of Chasmosaurus belli, C. irvinensis, and C. russelli.
This leaves Pentaceratops and Chasmosaurus mariscalensis sharing the most similarities (both ancestral and derived) with the Williams Fork specimen. Given both the subadult condition and rather biogeographically isolated status of the Williams Fork specimen, a more definitive taxonomic assessment is not warranted. The information at hand does suggest, however, that a southern member of the Chasmosaurus/Pentaceratops clade existed as far north as present-day northwestern Colorado near the Campanian/ Maastrichtian boundary.

Even given the fragmentary nature of the Williams Fork specimen, our results do correspond with northern and southern groupings found by Holmes et al. (2001) within the Chasmosaurus/ Pentaceratops clade. They found a northern clade composed of the Albertan taxa Chasmosaurus belli, C. irvinensis, and C. russelli. The southern group of Pentaceratops and Chasmosaurus mariscalensis, from New Mexico and Texas, respectively, do not form a clade, but along with the Williams Fork specimen from somewhat farther north in Colorado, do seem to indicate a cluster of taxa in the more southern part of the Western Interior versus a distinctly northern clade. Lehman $(1989,1990,1993,1996)$ has suggested that there might well be some sort of north to south cline of chasmosaurine taxa. In combination with the results of Holmes et al. (2001), the information from the Williams Fork specimen supports this thesis.

\section{ACKNOWLEDGMENTS}

The results presented here were part of the master's thesis of the first author. P. Adam, P. Dodson, C. Forster, T. Lehman, S. Sampson, and C. Forster provided helpful suggestions on the manuscript. P. Adam created the location map. B. Weinman of Beehive Productions is thanked for creating illustrations of the Williams Fork skull. Cory Redman supplied taxonomic information. We thank the students of SDSU for collecting the skull and the SDMNH for preparing it. Financial support for field work in Colorado was provided by the National Science Foundation (NSF\# 8905020) and the American Chemical Society (PRF\# 15917-B2 and 18342-B2-C).

\section{REFERENCES}

ARChIBALD, J. D. 1987. Late Cretaceous (Judithian and Edmontonian) vertebrates and geology of the Williams Fork Formation, NW Colorado, p. 7-11. In P. J. Currie and E. H. Koster (eds.), Fourth Symposium on Mesozoic Terrestrial Ecosystems. Tyrrell Museum of Paleontology, Drumheller, Occasional Paper 3.

BRown, B. 1914. Anchiceratops, a new genus of horned dinosaurs from the Edmonton Cretaceous of Alberta. With discussion of the origin of the ceratopsian crest and the brain casts of Anchiceratops and Trachodon. Bulletin of the American Museum of Natural History, 33:539548.

Cobban, W. A. 1958. Two new species of Baculites from the Western Interior region. Journal of Paleontology, 32:660-665.

Cobban, W. A. 1962. Baculites from the lower part of the Pierre Shale and equivalent rocks in the Western Interior. Journal of Paleontology, 36:704-718.

Cullins, H. L. 1971. Geologic map of the Banty Point Quadrangle, Rio Blanco County, Colorado. U.S. Geological Survey, Map GQ-703, 1: 24,000 .

DiEM, S. D. 1999. Vertebrate faunal analysis of the Upper Cretaceous Williams Fork Formation, northwestern Colorado. Unpublished master's thesis, San Diego State University, $188 \mathrm{p}$.

Dodson, P., AND P. J. Currie. 1988. The smallest ceratopsid skullJudith River Formation of Alberta. Canadian Journal of Earth Sciences, 25:926-930.

Dodson, P., AND P. J. CURRIE. 1990. Neoceratopsia, p. 593-618. In D. B. Weishampel, P. Dodson, and H. Osmólska (eds.), The Dinosauria. University of California Press, Berkeley.

DYNI, J. R. 1968. Geologic map of the Elk Springs quadrangle, Moffat County, Colorado. U.S. Geological Survey Geologic Quadrangle Map GQ-702, scale 1:24,000. 
Eberth, D. A. 1997. Edmonton Group, p. 199-204. In P. J. Currie and K. Padian (eds.), The Encyclopedia of Dinosaurs. Academic Press, San Diego.

EliAs, M. K. 1933. Cephalopods of the Pierre Formation of Wallace County, Kansas, and adjacent area. University of Kansas Science Bulletin, 21:289-363.

Forster, C. A., P. C. Sereno, T. W. Evans, And T. Rowe. 1993. A complete skull of Chasmosaurus mariscalensis (Dinosauria: Ceratopsidae) from the Aguja Formation (Late Campanian) of West Texas. Journal of Vertebrate Paleontology, 13(2):161-170.

Gill, J. R., AND W. S. CoBBAn. 1966. The Red Bird section of the Upper Cretaceous Pierre Shale in Wyoming. U.S. Geological Survey Professional Paper, 393A:A1-A73.

Gilmore, C. W. 1946. Reptilian Fauna of the North Horn Formation of Central Utah. United States Geological Survey Professional Paper, 210C:29-53.

GoDFREY, S. J., AND R. HolmEs. 1995. Cranial morphology and systematics of Chasmosaurus (Dinosauria: Ceratopsidae) from the Upper Cretaceous of western Canada. Journal of Vertebrate Paleontology, 15: 726-742.

HANCOCK, E. T. 1925. Geology and coal resources of the Axial and Monument Butte quadrangles, Moffat County, Colorado. U.S. Geological Survey Bulletin, 757:1-134.

Harland, W. B., R. L. Armstrong, A. V. Cox, L. E. Craig, A. G. Smith, And D. G. Smith. 1990. A Geologic Time Scale 1989. Cambridge University Press, Cambridge, 263 p.

Holmes, R. B., C. A. Forster, M. Ryan, AND K. M. Shepherd. 2001. A new species of Chasmosaurus from the Dinosaur Park Formation of southern Alberta. Canadian Journal of Earth Sciences, 38:1423-1438.

HoRNER, J. R., AND P. J. CURRIE. 1994. Embryonic and neonatal morphology and ontogeny of a new species of Hypacrosaurus (Ornithischia, Lambeosauridae) from Montana and Alberta, p. 312-336. In K. Carpenter, K. F. Kirsch, and J. R. Horner (eds.), Dinosaur Eggs and Babies. Cambridge University Press, Cambridge.

Kitely, L. W. 1983. Paleogeography and eustatic-tectonic model of late Campanian Cretaceous sedimentation, southwestern Wyoming and northwestern Colorado, p. 273-303. In M. W. Reynolds and E. D. Dolly (eds.), Mesozoic paleogeography of the west-central United States. Society of Economic Paleontologists and Mineralogists Rocky Mountain Paleogeography Symposium, 2.

LAMBE, L. M. 1902. New genera and species From the Belly River Series (mid-Cretaceous). Contributions to Canadian Paleontology, 3:25-81.

LAMBE, L. M. 1915. On Eoceratops canadensis, gen. nov., with remarks on the other genera of Cretaceous horned dinosaurs. Geological Survey of Canada Museum Bulletin, 12:1-49.

LAWTON, T. F. 1983. Late Cretaceous fluvial systems and the age of foreland uplifts in central Utah, p. 181-199. In J. E. Lowell (ed.), Rocky Mountain foreland basins and uplifts. Rocky Mountain Association of Geologists.

Lawton, T. G. 1986. Fluvial systems of the Upper Cretaceous Mesaverde Group and Paleocene North Horn Formation, central Utah: a record of transition from thin-skinned to thick-skinned deformation in the foreland region, p. 423-442. In J. A. Peterson (ed.), Paleotectonics and Sedimentation in the Rocky Mountain Region, United States. American Association of Petroleum Geologists Memoir, 41.

LeHMAN, T. M. 1989. Chasmosaurus mariscalensis, n. sp., a new ceratopsian dinosaur from Texas. Journal of Vertebrate Paleontology, 9: $137-162$.

LeHman, T. M. 1990. The ceratopsian subfamily Chasmosaurinae: sexual dimorphism and systematics, p. 211-229. In K. Carpenter and P. J. Currie (eds.), Dinosaur Systematics Approaches and Perspectives. Cambridge University Press, Cambridge.

Lehman, T. M. 1993. New data on the ceratopsian dinosaur Pentaceratops sternbergii Osborn from New Mexico. Journal of Paleontology, 67:279-288

Lehman, T. M. 1996. A horned dinosaur from the El Picacho Formation of West Texas, and review of ceratopsian dinosaurs from the American southwest. Journal of Paleontology, 70:494-508.

Lillegraven, J. A., AND L. M. Ostresh JR. 1990. Late Cretaceous (earliest Campanian/Maastrichtian) evolution of western shorelines of the North American Western Interior Seaway in relation to known mammalian faunas, p. 1-30. In T. M. Bown and K. D. Rose (eds.), Dawn of the age of mammals in the northern part of the Rocky Mountain Interior, North America. Geological Society of America Special Paper, 243.

LulL, R. S. 1933. A revision of the Ceratopsia or horned dinosaurs. Peabody Museum of Natural History Bulletin, 3, 175 p.

MARSH, O. C. 1888. A new family of horned Dinosauria from the Cretaceous. American Journal of Science, ser. 3, 36:477-478.

MARSH, O. C. 1889. Notice of gigantic horned Dinosauria from the Cretaceous. American Journal of Science, ser. 3, 38:173-175.

MARSH, O. C. 1891. Notice of new vertebrate fossils. American Journal of Science, ser. 3, 42:265-269.

MeEK, F. B., AND F. V. HAYDEN. 1856. Descriptions of new species of Gastropoda and Cephalopoda from the Cretaceous formations of $\mathrm{Ne}$ braska Territory. Proceedings of the Academy of Natural Sciences of Philadelphia, 8:63-72.

Meek, F. B., AND F. V. Hayden. 1861. Descriptions of some Lower Silurian (Primordial), Jurassic, Cretaceous and Tertiary fossils collected in Nebraska by the exploring expedition under the command of Captain W. F. Reynolds, U.S. Topographical Engineer, with some remarks on the rocks from which they were obtained. Proceedings of the Academy of Natural Sciences of Philadelphia, 12:175-185.

Newman, K. R. 1987. Biostratigraphic correlation of Cretaceous-Tertiary boundary rocks, Colorado to San Juan Basin, New Mexico, p. 151163. In J. E. Fassett and J. K. Rigby Jr. (eds.), Cretaceous-Tertiary Boundary in the San Juan and Raton Basins, New Mexico and Colorado. Geological Society of America Special Paper, 209.

NoLL, M. D. 1988. Sedimentology of the Upper Cretaceous Williams Fork Formation, Rio Blanco County, northwestern Colorado. Unpublished master's thesis, San Diego State University, 210 p.

Obradovich, J. D., AND W. A. CobBan. 1975. A time-scale for the Late Cretaceous of the western interior of North America, p. 31-54. In W. G. E. Caldwell (ed.), The Cretaceous System in the Western Interior of North America. Geological Association of Canada Special Paper, 13 .

Osborn, H. F. 1923. A new genus and species of Ceratopsia from New Mexico, Pentaceratops sternbergii. American Museum Novitates, 93: $1-3$.

PARKS, W. E. 1925. Arrhinoceratops brachyops, a new genus and Species of Ceratopsia from the Edmonton Formation of Alberta. Toronto University Studies, Geological Series, 19:1-15.

Rowe, T., E. H. ColberT, AND J. D. NATiONs. 1981. The occurrence of Pentaceratops (Ornithischia: Ceratopsia) with a description of its frill, p. 29-48. In S. Lucas, J. K. Rigby Jr., and B. S. Kues (eds.), Advances in San Juan Basin Paleontology. University of New Mexico Press, Albuquerque.

RyAN, M. J., AND A. P. Russell. 2001. Dinosaurs of Alberta (exclusive of Aves), p. 279-297. In D. H. Tanke and K. Carpenter (eds.), Mesozoic Vertebrate Life: New Research Inspired by the Palaeontology of Philip J. Currie. Indiana University Press, Bloomington.

SAmpson, S. D., M. J. RyAn, AND D. H. TANKE. 1997. Craniofacial ontogeny in centrosaurine dinosaurs (Ornithischia: Ceratopsidae): taxonomic and behavioral implications. Zoological Journal of the Linnean Society, 121:293-337.

SeELEy, H. G. 1888. The classification of the Dinosauria. Report of the British Association for the Advancement of Science, 1887:698-699.

STERNBERG, C. M. 1940. Ceratopsidae from Alberta. Journal of Paleontology, $14: 468-480$

WhITFIELD, R. P. 1877. Preliminary report on the paleontology of the Black Hills, containing descriptions of new species of fossils from the Potsdam, Jurassic, and Cretaceous formations of the Black Hills of Dakota. U.S. Geographical and Geological Survey of the Rocky Mountain Region Report (Powell), p. 1-49.

ZEILER, R. M. 1987. Stratigraphy and palynology of Late Cretaceous and Early Tertiary rocks, Tommy's Dray, Rio Blanco County, Colorado. Geological Society of America Rocky Mountain Section Abstracts with Programs, 19:344.

ACCEPTEd 3 MAy 2004 